\title{
Store tobacco policies: a survey of store managers, California, 1996-1997
}

\author{
Zipora Weinbaum, Valerie Quinn, Todd Rogers, April Roeseler
}

California Department of Health Services,

Tobacco Control

Section, 601 North 7 th

Street, Sacramento,

California 95814, USA

Z Weinbaum

V Quinn

A Roeseler

Public Health

Consultant, 101 First

Street, Suite 426, Los

Altos, California 94022,

USA

T Rogers

Correspondence to:

$\operatorname{Dr} Z$ Weinbaum, California

Department of Health

Services, Maternal and Child

Health Branch,

Epidemiology and Evaluation

Section, 714 P Street, Room

476, Sacramento, California

95814, USA.

email: zweinbau@dhs.ca.gov

Received 19 June 1998

Revision received 2 March

Revision
1999

Accepted 3 April 1999

\begin{abstract}
Objective-To identify store tobacco policies and retailer perception and beliefs that may have contributed to changes in compliance with youth access laws in California.

Design-In the winter of 1996-7, a cross sectional, follow up telephone survey was conducted of California store managers whose stores were anonymously surveyed for illegal tobacco sales in the summer of 1996 (that is, 1996 Youth Tobacco Purchase Survey, YTPS).

Setting-A simple random sample of stores from a list of California stores likely to sell tobacco, used in the 1996 YTPS.

Participants-334 managers (77\%) of the 434 stores surveyed in 1996 responded to the survey. After eliminating stores that stopped selling tobacco or were under new management or ownership, 320 responses of store managers were included in the analysis. The stores were analysed by type of ownership: chain, which included corporate managed $(n=61)$; franchise owned ( $n=56)$; and independent $(n=203)$. Main outcome measures-Responses of store managers were linked with the 1996 YTPS outcomes. Manager responses were compared by $\chi^{2}$ tests. Logistic regression analyses were conducted to identify store factors associated with illegal tobacco sales.
\end{abstract}

Results-A lower likelihood of illegal sales rate was associated with the chain stores when compared with the independent stores (odds ratio $(\mathrm{OR})=0.4,95 \%$ confidence interval (CI) 0.2 to 0.9 ). A lower likelihood of illegal tobacco sales was found in stores that implemented tobacco related activities in the previous year such as changing tobacco displays $(\mathrm{OR}=0.5,95 \% \mathrm{CI} 0.2$ to 0.9$)$ or adding new warning signs $(\mathrm{OR}=0.7,95 \%$ CI 0.4 to 1.2). Store managers' beliefs that youth were sent to their stores to do compliance checks also resulted in a lower likelihood of illegal sales $(\mathrm{OR}=0.7,95 \%$ CI 0.4 to 1.1).

Conclusions-Store tobacco youth access policies, and managers' beliefs about the extent of youth access enforcement in the community, are important in reducing illegal tobacco sales to minors.

(Tobacco Control 1999;8:306-310)

Keywords: legislation; retail stores; youth access
The federal Synar Amendment (PHS Act Section No 1926) requires states receiving funds for prevention and treatment of substance abuse to enforce laws to reduce illegal sales of tobacco to minors. In response to the Synar Amendment, California enacted the Stop Tobacco Access to Kids Enforcement (STAKE) Act in 1994, and started to enforce the law in December 1995. The STAKE Act requires tobacco retailers to check identification of young people who appear to be less than 18 and to post warning signs at each point of purchase. The law also requires the California Department of Health Services (CDHS) to conduct statewide enforcement activities and to maintain a toll-free number for the public to report illegal sales to minors. CDHS is required to conduct statewide annual assessments of illegal tobacco sales to minors, the Youth Tobacco Purchase Surveys (YTPS). Statewide estimates of illegal sales rates showed a significant reduction $(\mathrm{p}<0.05)$ in illegal sales to minors between the summer of 1995 (before implementation of the STAKE Act $-37.0 \%$ illegal sales), and the summer of 1996 (following implementation of the STAKE Act-29.3\% illegal sales). ${ }^{1}$

Relatively few studies have examined how store policies and retailer attitudes and beliefs are associated with youth access to tobacco, and most of these studies have been conducted at the community level..$^{2-7}$ Overall, the studies conclude that the best way to limit youth access to tobacco is an ongoing combination of community education, retailer and corporate education, and statewide and local enforcement. Woodruff et al found that changes in knowledge and attitudes of retailers were weakly associated with positive changes in behaviours, leading them to conclude that environmental, sociocultural, and situational factors may be necessary to change retailer behaviour. ${ }^{8}$ More recently, deterrence theory was used to design a community based intervention to increase merchant perception of risk of being detected non-compliant with youth tobacco access policies. ${ }^{9}$

This study was conducted to identify tobacco store policies, and retailer perceptions and beliefs that may have contributed to changes in compliance with youth access laws in California.

\section{Methods}

YOUTH TOBACCO PURCHASE SURVEYS (YTPS) The YTPS are statewide annual random surveys of tobacco sales to young people. As California does not have tobacco retailer licensing, a list of stores likely to sell tobacco 
(including convenience stores, gas stations, drug stores, liquor stores, supermarkets, and tobacco stores) was obtained from the California State Board of Equalization. A simple random sample of nearly 1000 stores was drawn from the list, and stores that were no longer in business or did not sell tobacco were eliminated. Initially, the random sample was calculated to allow for a final target sample of at least 384 , within $5 \%$ of the true value with $95 \%$ confidence.

About 60 young people from diverse backgrounds, 15-16 years old and including both boys and girls, were recruited each year. These youngsters went into the stores and attempted to purchase tobacco. The youngster either placed the tobacco on the counter or requested a tobacco product from the clerk. On occasions when the clerk rung up the sale, the youngster indicated that they did not have the money, apologised, and left the store. If the clerk rang up the sale on the cash register, the transaction was recorded as a sale. An adult escort who recorded additional information about the store witnessed each attempted buy. It should be emphasised here that the YTPS are not associated with enforcement activities; they only serve as assessment tools. Furthermore, the survey activities and young people involved remain anonymous to ensure as realistic an assessment of illegal sales rates as possible. Survey instruments were transferred to CDHS, double entered, and analysed using Statistical Analysis Software (SAS).

In response to the requirements of the STAKE Act, CDHS conducted the first YTPS in the summer of 1995 in California. The results of this survey (illegal sales rate of $37.0 \%$ ) were used as a baseline before implementation of the youth access educational and enforcement activities in December of 1995. Similarly, the second YTPS survey, conducted during the summer of 1996 (illegal sales rate of $29.3 \%$ ), was carried out to assess progress in implementation of the STAKE Act. ${ }^{1}$

STORE MANAGER FOLLOW UP STUDY

Between December 1996 and March 1997, a telephone follow up study of managers of stores that were surveyed during 11 June 1996 to 26 July 1996 in the statewide YTPS was conducted, using the CDHS computer assisted telephone interviews (CATI) unit of the Cancer Control Branch. When calling, the interviewers identified themselves as members of the California Department of Health Services. The survey instrument had 48 questions, some of which dealt with the type and environment of the stores, while others dealt with sources of knowledge and the knowledge of policies and laws with regard to tobacco sales to minors. Managers were asked about the store environment in relation to tobacco products, about employee policies initiated during the previous year, and about manager beliefs and perceptions of the enforcement of tobacco related policies in their communities at present and over the past year or two.
Among the original 434 stores surveyed in the 1996 YTPS, 66 store managers were not available during five telephone contact trials, 17 stores had disconnected phone numbers, 14 store managers could not communicate at all in English, and three store managers had specific instructions from their corporate offices not to interact with our interviewers (total of 100 non-respondents). The remaining 334 store managers were willing to talk to our interviewers, yielding a $77 \%$ response rate.

After eliminating responses from store managers who stopped selling tobacco, stores under new ownership (or management), and store managers who could not identify their type of ownership, the final analysis was performed on responses of 320 store managers, or $74 \%$ of managers of the stores surveyed in 1996. Only responses of store managers who could discuss policies and activities in the previous year were included in the survey. Results of the responses of the store managers were linked with the 1996 YTPS data to identify store policies that may be associated with the overall decrease in illegal tobacco sales. The proportion of illegal sales in this sample was almost identical $(29.4 \%)$ to the overall rate of $29.3 \%$ in the 1996 YTPS. The stores were stratified and analysed by type of ownership: corporate managed ("chain") ( $\mathrm{n}=$ $61,19 \%)$, franchise $(n=56,17.5 \%)$, and independent $(n=203,63.4 \%)$. Where appropriate, store manager responses were compared to the 1996 YTPS survey results using the $\kappa$ statistic. The association between responses of store managers (location of tobacco in store, using help in prompting to request identification, awareness of the STAKE Act, changing tobacco displays in the previous year, adding new warning signs, believing that youngsters were intentionally sent to stores to do compliance checks, receiving incentives from tobacco industry, need of educational materials in a language other than English) and illegal tobacco sales (yes, no) were tested in multiple logistic regressions using PROC LOGISTIC in SAS.

\section{Results}

The following was the breakdown of store types as reported by the managers: convenience stores and small markets, 30.9\%; convenience stores with gas (petrol), 23.4\%; liquor stores, $13.1 \%$; supermarkets, $11.9 \%$; drug stores/pharmacies, $7.2 \%$; gas stations $3.8 \%$; other, $9.7 \%$.

Store manager respondents represent the wide ethnic diversity of California. Over half the store managers said that they were interested in educational materials about the STAKE Act in a language other than English. A majority of those requested materials in Spanish (68.0\%), followed by Korean (6.2\%), Arabic (4.9\%), Vietnamese $(4.5 \%)$, and other languages such as Chinese/Mandarin, Thai, Hindi, Punjabi, Laotian, Persian, Tagalog, and European languages.

As explained in the Methods section, stores were analysed by type of ownership. Since ownership was categorised in the 1996 YTPS 
as chain and independent, chain and franchise categories were combined into one variable in the $\kappa$ analyses. Responses of the store managers were in moderate agreement with the 1996 YTPS observations for two variables: type of store $(\kappa=0.62)$ and ownership $(\kappa=$ 0.62 ).

Below are key responses of store managers, which are also summarised in table 1.

LOCATION OF TOBACCO IN THE STORES

Thirty six per cent of the store managers said that they had open (self service) tobacco displays while $64.4 \%$ had clerk assisted displays. This proportion was similar for franchise and independent stores, but was different for the chain stores, where only $50.8 \%$ of these store managers said that they had self service displays $(\mathrm{p}<0.05)$.

CHECKING FOR AGE AND/OR IDENTIFICATION Most store managers $(99.7 \%)$ said that they had a policy of checking young people for identification before selling tobacco to them. There was some inconsistency about the age a person should appear to be before they are asked for identification (ID): $13.4 \%$ said a person should appear to be under $18,52.5 \%$ said under 25 , and $33.1 \%$ said under 30 years of age. Nineteen per cent of all stores were using electronic scanners at the cash register to prompt ID checking, but the use of the electronic scanners among the store types varied, with $65.6 \%$ of the chain stores having electronic scanners $v 6.9 \%$ of the independent stores $(p<0.05)$. Similarly, the use of electronic calendars that help cashiers verify age varied by store type, with $42.6 \%$ of the chain stores $v 7.9 \%$ of the independent stores having such electronic calendars $(p<0.05)$. However, $69 \%$ of the independent stores reported using paper calendars to help with age verification.

AWARENESS OF THE STAKE ACT

Sixty six per cent of store managers said that they had heard about the STAKE Act. Store managers' awareness of the STAKE Act varied across the store type, with $82.0 \%$ of the corporate managed, $71.4 \%$ of the franchise owned, and $59.1 \%$ of the independent store managers claiming familiarity with the law. Overall, $71.4 \%$ said that they heard about the STAKE Act from the media, followed by communications from the California Department of Health Services (56.2\%), followed by local tobacco distributors or wholesalers $(52.4 \%)$. No statistical association was observed between the source of the information about the STAKE Act and the illegal sales rate.

\section{INCENTIVES AND DISCOUNTS BY TOBACCO}

COMPANIES

Thirty four per cent of store managers said that they received discounts or incentives to display tobacco promotional materials. Tobacco brands most mentioned as having provided discounts or incentives for displaying tobacco promotional materials were Marlboro (55.6\%), Camel (35.2\%), and GPC (22.2\%). Types of incentive received from the tobacco companies were: free promotional display racks $(70.4 \%)$, cash payments $(64.8 \%)$, and discounts on wholesale price of the products $(61.1 \%)$.

Additional responses of store managers are summarised below (data are not presented).

TRAINING OF NON-FAMILY EMPLOYEES

Unfortunately, training questions were asked only of those store managers who employed non-family members. Ninety six per cent of stores employing non-family members ( $\mathrm{n}=$ 190) instituted some tobacco related training for their employees. Most of the training was for new employees (93.7\%), followed by periodic discussions with employees $(91.6 \%)$ and by posting notices in break and changing areas $(72.6 \%)$.

TOBACCO RELATED CHANGES IN THE STORES IN THE PREVIOUS YEAR

Corporate managed stores were most likely to have implemented and updated tobacco related activities in the previous year. These included: (1) aides in checking identification,

Table 1 Store manager tobacco related policies, knowledge, and beliefs California, 1996-1997

\begin{tabular}{|c|c|c|c|c|c|}
\hline & \multicolumn{3}{|l|}{ Store typet } & \multirow[b]{2}{*}{$\begin{array}{l}\text { Total } \\
(n=320) \\
n(\%)\end{array}$} & \multirow[b]{2}{*}{$\underset{\left(\chi^{2} \text { test }\right)}{p \text { Value }}$} \\
\hline & $\begin{array}{l}\text { Chain } \\
(n=61) \\
n(\%)\end{array}$ & $\begin{array}{l}\text { Franchise } \\
(n=56) \\
n(\%)\end{array}$ & $\begin{array}{l}\text { Independent } \\
(n=203) \\
n(\%)\end{array}$ & & \\
\hline \multicolumn{6}{|l|}{ Location of tobacco in the stores } \\
\hline Self service & $31(50.8)$ & $18(32.1)$ & $65(32.0)$ & $114(35.6)$ & \multirow[t]{2}{*}{$<0.05$} \\
\hline Clerk assisted & $30(49.2)$ & $38(67.9)$ & $138(68.0)$ & $206(64.4)$ & \\
\hline \multicolumn{6}{|l|}{ Policy in store to check age for tobacco purchase } \\
\hline How old does a customer have to appear to ask & & & & & \\
\hline Under 18 & $1(1.6)$ & $4(7.1)$ & $38(18.7)$ & $43(13.4)$ & \multirow[t]{3}{*}{$<0.05$} \\
\hline Under 25 & $27(44.3)$ & $28(50.0)$ & $113(55.7)$ & $168(52.5)$ & \\
\hline Under 30 & $33(54.1)$ & $24(42.9)$ & $49(24.1)$ & $106(33.1)$ & \\
\hline Age requested verbally & $1(1.6)$ & $2(3.6)$ & $3(1.5)$ & $6(1.9)$ & NS \\
\hline Check ID & $61(100.0)$ & $56(100.0)$ & $202(99.5)$ & $319(99.7)$ & NS \\
\hline Electronic scanner in the store & $40(65.6)$ & $8(14.3)$ & $14(6.9)$ & $62(19.4)$ & $<0.05$ \\
\hline Electronic calendar in the store & $26(42.6)$ & $5(8.9)$ & $16(7.9)$ & $47(14.7)$ & $<0.05$ \\
\hline Paper calendar in the store & $29(47.5)$ & $47(83.9)$ & $140(69.0)$ & $216(67.5)$ & $<0.05$ \\
\hline Awareness of the STAKE Act & $50(82.0)$ & $40(71.4)$ & $120(59.1)$ & $210(65.6)$ & $<0.05$ \\
\hline $\begin{array}{l}\text { Received discounts or incentives for displaying } \\
\text { tobacco promotional materials in the last year }\end{array}$ & $12(19.7)$ & $28(50.0)$ & $68(33.5)$ & $108(33.8)$ & $<0.05$ \\
\hline
\end{tabular}

t Owing to missing values numbers may not add up to totals.

$\star \chi^{2}$ tests compare the chain, franchise, and independent store types.

ID, identification. 
including innovations in practices and activities, such as installing electronic scanners at the cash register $(18.0 \%$ of chain stores, $1.8 \%$ of franchise stores, $2.5 \%$ of independent stores) or installing electronic calendars $(14.8 \%$ of chain stores, $5.4 \%$ of franchise stores, $2.5 \%$ of independent stores); (2) changing tobacco displays $(32.8 \%$ of chain stores, $37.5 \%$ of franchise stores, $25.1 \%$ of independent stores); and (3) adding warning signs $(72.1 \%$ of chain stores, $60.7 \%$ of franchise stores, $52.2 \%$ of independent stores) $(\mathrm{p}<0.05)$.

BELIEFS ABOUT STORE COMPLIANCE

ENFORCEMENT IN THE PAST YEAR

Forty four per cent of store managers believed that youngsters were intentionally sent to their stores to do compliance checks. This proportion was similar for all store types.

BELIEFS ABOUT THE STORE'S CHANCES OF BEING CAUGHT WHEN SELLING TOBACCO

UNINTENTIONALLY

Fifty seven per cent of all store managers believed that there was a low chance of their stores being caught unintentionally selling tobacco to minors. Thirty three per cent of the corporate store, $26.8 \%$ of franchise owned, and $24.1 \%$ of independently owned store managers believed that there was a high chance of their stores being caught.

BELIEFS ABOUT TOBACCO SALES TO MINORS IN ONE'S COMMUNITY

Twenty eight per cent of the store managers believed that at least half of the stores in their communities were currently selling tobacco to minors, but $41.6 \%$ of store managers believed that at least half of the stores in their communities sold tobacco to minors in the year or two before the survey.

STORE POLICY FACTORS IN NON-COMPLIANCE WITH THE LAW

Results of two multiple regression analyses are presented in table 2 . The first analysis tested the association between store types and illegal sales, the second analysis tested the relation between the store environment variables described above and illegal sales, controlled for store type.

Illegal tobacco sales rates varied across the type of store ownership: $18.0 \%$ of the corporate managed, $25.0 \%$ of the franchise

Table 2 Factors associated with illegal sales California, 1996-1997 (multiple logistic regressions)

\begin{tabular}{|c|c|c|c|}
\hline & Sale $n(\%)$ & Total n (\%) & $\begin{array}{l}\text { Odds ratio } \\
(95 \% \text { CI })\end{array}$ \\
\hline \multicolumn{4}{|l|}{ (A) Type of ownership } \\
\hline Independent & $69(34.0)$ & $203(63.4)$ & 1.0 \\
\hline Franchise & $14(25.0)$ & $56(17.5)$ & $0.6(0.3$ to 1.3$)$ \\
\hline Chain & $11(18.0)$ & $61(19.1)$ & $0.4(0.2$ to 0.8$)$ \\
\hline \multicolumn{4}{|l|}{ (B) Manager responses ${ }^{\star}$} \\
\hline Adding new warning signs in the previous year & $42(25.6)$ & $164(60.3)$ & $0.7(0.4$ to 1.2$)$ \\
\hline Changing tobacco displays in the previous year & $15(18.1)$ & $84(30.9)$ & $0.5(0.2$ to 0.9$)$ \\
\hline $\begin{array}{l}\text { Beliefs that youngsters were sent intentionally } \\
\text { to the respondents' store to do compliance } \\
\text { checks }\end{array}$ & $36(25.5)$ & $141(51.8)$ & $0.7(0.4$ to 1.1$)$ \\
\hline
\end{tabular}

* 48 records with missing responses were excluded from this analysis

$\mathrm{CI}$, confidence interval. owned, and $34.0 \%$ of the independent stores were willing to sell cigarettes to young people before the telephone survey (summer of 1996). There was a lower likelihood of illegal sales in the chain stores than in the independent stores (odds ratio $(\mathrm{OR})=0.4,95 \%$ confidence interval (CI) 0.2 to 0.8 ) (table $2 \mathrm{~A}$ ). When testing store manager responses and controlling for store type, the following variables were identified as predictors of illegal sales in a multiple regression analysis: changing tobacco displays in the previous year $(\mathrm{OR}=0.5,95 \% \mathrm{CI}$ 0.2 to 0.9 ), adding warning signs in the previous year $(\mathrm{OR}=0.7,95 \% \mathrm{CI} 0.4$ to 1.2$)$, and store managers' belief that youngsters were sent intentionally to their stores to do compliance checks $(\mathrm{OR}=0.7,95 \%$ CI 0.4 to 1.1) (table 2B).

\section{Discussion}

The results of our survey show that most stores in California are making efforts to reduce sales of tobacco to minors. Changes in store policies and practices regarding tobacco sales to young people were found to be most prevalent in corporate owned chain stores and these changes were associated with reduced tobacco sales to minors over the one year period.

The results of our study suggest that store manager awareness of the need for tobacco related policies may be an important factor in reducing illegal sales of tobacco to minors. The awareness of the need to reduce illegal sales may be a motivator to start working on this problem. Store managers who are concerned about illegal tobacco sales to young people will try to implement changes that may help in reducing sales of tobacco to minors. Managers reported store changes in tobacco displays, but those did not necessarily result in only having clerk assisted displays. Changes in tobacco displays cover a wide range of activities such as physically moving displays, decreasing the number of cigarette packs, reducing the number of tobacco displays, locking up other tobacco products such as cigars or cartons, moving the displays further from the customer's reach, away from candy displays, better in clerk's view, into overhead displays, and so on.

Manager activities by themselves are obviously not sufficient to solve the illegal sales problem. In this study we did not observe that a clerk-assisted-only environment is associated with reduced illegal tobacco sales. The clerk selling tobacco has to be aware of the fact that a young person is attempting to buy cigarettes before they ask for identification. Otherwise, they may sell tobacco to a minor regardless of the store environment.

It should be noted here that this is a cross sectional study, allowing conclusions about associations between store manager activities and the outcome of illegal sales, but not about causality between store manager activities and the resultant illegal sales. This study depends on recall of activities and may be a subject to recall bias. Longitudinal cohort studies would provide more valid data for understanding causality. 
Because we cannot tell whether the changes in the stores were made before or after the 1996 survey, we are only measuring the sensitivity of the store manager to tobacco related youth access issues. As the implementation of these activities had happened at some point a year before the survey, in the period after the 1995 YTPS, it would appear that there is some association between the activities and the reduction in illegal sales observed in the 1996 YTPS.

The difficulty in collecting reliable store information is expressed in the moderate agreement obtained on the variables tested in our survey compared with the 1996 YTPS. One difficulty lies in having a clear definition of the type of store, another in the ownership of the store. While one may assume that a store is under corporate ownership, it may be franchised or independent, and in this case some of the corporate behaviour expectations are not fulfilled. Similarly, for research examining associations with store types it is necessary to have very tight store definitions, which may not be similar to the definition of the store manager.

Owing to the small sample size and the resultant low power, confidence intervals were too wide to obtain statistically significant effects. For example, addition of warning signs when tested in univariate analyses was shown to be statistically significant. Obviously, results of the statistical tests may reflect accurately that no significant effects were present.

Addiction literature is abundant, with research examining the relation between community attitudes about drug abuse, the resulting behaviours, and community norms. ${ }^{10-13}$ In this study, as in the Schofield study, ${ }^{10}$ we observed differences in behaviour, knowledge, attitudes, and self reported practices of managers depending upon the type of store in which they work. Changes in policies and practices are more difficult to instigate in populations of independent stores than in corporate owned stores, for obvious reasons (for example, centralised management and decision making, availability of resources).

The data presented here describe the changes that have been occurring in California with regard to tobacco sales to minors and show possible reasons for some of the changes observed. The decrease in the illegal sales to youngsters from 1995 to 1996 coincided with reported changes in the store environments, in certain policies and practices, and in perceptions of store managers about tobacco sales to young people and their risks in selling tobacco to minors. Interestingly, the change in perceptions about tobacco sales to minors within the communities reflects the overall changes in the statewide illegal sales rates.
Forty two per cent of the store managers in our survey believed that most or all stores in their communities were selling tobacco to minors during the previous year or two, while in 1995 the illegal sales rate in California was $37.0 \%$. Twenty eight per cent of store managers held similar beliefs in 1996, the illegal sales rate for that year being $29.3 \%$. This situation can be described as a "community norm change" between the two years, but we are not able to tell whether the change in the illegal sales precedes the perceptions of the store managers or vice versa.

The decrease in illegal sales of tobacco to minors is likely to be caused by a combination of public health policies and activities with regard to tobacco use in California. Statewide enforcement increased local enforcement, increased educational efforts, and publicity over the new FDA rules are all probable contributors to the store level changes observed in this study. The store changes are indicative of community norm changes. Continuing efforts to enhance and maintain these community norm changes are clearly needed.

Bonnie Davis PhD, Chief, Computer Assisted Telephone Interviews (CATI) Unit of the Cancer Control Branch, CDHS, assisted with the construction of the survey instrument. The excellent work and competency of the CATI Unit interviewers is greatly appreciated.

1 US Centers of Disease Control and Prevention. Estimates of retailers willing to sell tobacco to minors-California, August-September 1995 and June-July 1996. MMWR 1996;45:1095-9.

2 Altman DG, Rasenick-Douss L, Foster V, et al. Sustained effects of an educational program to reduce sales of cigarettes to minors. Am F Public Health 1991;81: 891-3.

3 Feighery E, Altman DG, Shaffer G. The effects of combining education and enforcement to reduce tobacco sales to minors. A study of four northern California communities. 7AMA 1991;266:3168-71.

4 Wildey MB, Woodruff SI, Agro A, et al. Sustained effects of educating retailers to reduce cigarette sales to minors. Public Health Rep 1995;110:625-9.

5 Abernathy TJ. Compliance for kids: a community-based tobacco prevention project. Can $\mathcal{f}$ Public Health 1994; 85:82-4.

6 Dovell RA, Mowat DL, Dorland J, et al. Changes among retailers selling cigarettes to minors. Can $\mathcal{F}$ Public Health 1996;87:66-8.

7 Altman DG, Linzer J, Kropp R, et al. Policy alternatives for reducing tobacco sales to minors: results from a national survey of retail chain and franchise stores. $\mathcal{F}$ Public Health Policy 1992;13:318-31.

8 Woodruff SI, Erickson AD, Wildey $\mathrm{MB}$, et al. Changing retailer knowledge, attitudes, and behaviors related to cigarette sales to minors. $\mathcal{F}$ Commun Psychol 1993;21:23445 .

9 Rogers T, Kropp R, Feighery E, et al. Kids Access to Tobacco Study (KATS). Paper presented at the annual meeting of the American Public Health Association (APHA), New York, USA, 1996.

10 Schofield MJ, Gulliver S, Sanson-Fisher RW. Retailer attitudes on tobacco sales to minors in New South Wales, Australia. Tobacco Control 1995;4:362-6.

11 Fitzpatrick JL, Gerard K. Community attitudes toward drug use: the need to assess community norms. Int $\mathcal{F}$ Addict 1993;28:947-57.

12 Aberg L. Drinking and driving: intentions attitudes, and social norms of Swedish male drivers. Accid Anal Prev 1993;25:289-96.

13 Godin G, Valois P, Lepage L, et al. Predictors of smoking behavior: an application of Ajzen's theory of planned behavior. Br f Addict 1992;87:1335-43. 